\title{
Formation of innovative methods for ecological safety systems of construction
}

\author{
Mikhail Slesarev, Valery Telichenko and Nguyen Dinh Dap* \\ Moscow State University of Civil Engineering, 129337, Yaroslavskoye Shosse 26, Moscow, Russia
}

\begin{abstract}
For the first time, formation of innovative methods for ecological safety of construction which called to treat as a result a complex of new technical solutions (more than 15 patents for inventions) focused on the solution of ecological safety problem in construction areas, and also for the first time the set four projects of national standards "“Green" standard. "Green" technologies of living environment and "green" innovative production»: - "Terms and definitions"; - "Classification"; - "Criteria of reference"; - "conformity assessment according to the requirements of the green standards. General provisions".
\end{abstract}

\section{Problem statement}

Proposed innovative methods of formation of ecological safety systems of construction (ESC) are based on two criteria for construction ecological safety, first, on minimization of the technical security requirements innovative construction environmental marketing and, secondly, on the minimization of environmental impacts of construction [1, 2, 3].

While entering the market, domestic construction science (activity aimed at the acquiring and application of new knowledge in construction) does not always dominate over old concept of creation and implementation of cost-oriented intellectual property products. Construction science strives to maximize profits with respect to mass production and intensified efforts for the marketing of the products made, whereas in the modern concept of socio-ethical economically oriented marketing focus and intellectual efforts of construction science must become environmentally oriented needs, preferences and tastes of end consumers of housing, buildings and so on, innovative methods of formation of ecological safety systems of construction [4].

The new concept of construction science and technology should focus on target segments of the environmental market, i.e. groups of construction products consumers with their economic needs, interests and preferences $[5,6]$.

To compete in the market of environmentally oriented innovations, flexibility and dynamics are required, i.e. the rapid firm adaptation to changing conditions of environmental market and demand for its products. Thus, the time factor is crucial. All the phases of the lifetime cycle of a new intellectual environmentally oriented building product

\footnotetext{
* Corresponding author: nguyendinhdap@gmail.com
} 
must be reduced: time for research and development, delivery of raw materials, construction operations time, order processing time, etc $[4,7,8]$.

For the first time, using innovative methods of formation for ecological safety systems of construction: innovative methods of critical technologies forecasting and method for solving innovative economic problems by linear programming with the properties of information, mathematical and simulation models that formalize solutions for the use of computers.

\section{Methods and results research}

\subsection{Method of forecasting the innovative economically oriented construction technologies}

Extensive development within a single technological mode reaches its resources restrictive limits. After that, under the influence of the growing number of accidents and disasters mechanisms of gradual replacement of the old technological mode with the new one are spontaneously activated. New construction technological mode is based on new construction technologies for the erection of new construction sites and new components of systems and complexes of construction machinery for new construction technologies oriented to resource saving and the use of new, previously unused resources.

A systematic method of promoting environmentally oriented innovations is based on examination of innovation - on procedure for the consideration of anything new in construction activity to determine eco-efficiency, including ecological safety. With regard to construction projects, the term "systematic method" involves the prediction of indicator system that can be expressed in terms of qualitative and quantitative indicators of ecological safety.

The levels of construction operations and components of systems of building technologies and construction projects are interdependent and restricted by all kinds of resources. In the structure of each technological mode there are changes of generations of construction structures, construction equipment, construction materials and construction technologies that do not coincide in the phase of their development. Techniques generations have different life cycle that leads to the harmonious nature of emergence process of critical construction technologies.

As the main directions for forecasting critical construction technologies, technologies of the following technological mode are recognized, which is most likely to become the main carrier of economic growth after the next economic restructuring. The choice of technology dominant at the moment as priority directions should be made with great care and careful consideration of the time factor, because the payback period of innovation should be much shorter than time reserve before the moral aging of the construction project or technology. Moral aging of construction object or technology is determined by the period of growth of its technological level, which ends with a plateau at the wave of technology generation.

The ability to increase the level of ecological safety at different kinds of construction projects and building technologies and products varies and, in addition, it changes at different periods of the life cycle of the generation of each kind of building structures and construction equipment. The potential for improving of one technology generation decreases with age, and when this potential is close to the minimum, this generation ceases to be reproduced and its individual representatives continue to exist only among individual consumers before their physical wear and tear.

Various types of equipment have different rates of improvements in accordance with inherent in each kind innovation potential depending mainly on the degree of possible 
integration of intelligent (human) potential. This period can be 10-20 years or more for slowly changing construction projects and types of construction techniques and technologies [9].

Examination of ecological safety of perspective construction products level is a probabilistic estimate of future area move, formed by ensemble of points $\boldsymbol{X}$ corresponding to ecological safety indicators, similar samples of construction products in K-dimensional information space [10].

The projected level of ecological safety is characterized by mathematical expectation and variance of each indicator of construction products for a certain period of forecasting. Research forecasting as examination element of innovations is carried out using probabilistic estimation methods. Normative forecasting as the procedure of environmental impact assessment of innovation, amounts to the construction of probabilistic areas of required protection functions and ecological safety parameters of construction products and technologies, and begins with the forecasting public needs, described as a set of long-term strategic aims for the implementation of a comfortable environment [9].

Construction innovative project life cycle begins with identifying needs, where, in fact, ecological, architectural, technical and other requirements for construction object are determined, and it ends after the full satisfaction of these requirements and utilization. In general, the life cycle of the innovative construction project consists of life cycles of the parts of building components, products and materials.

Eco-efficiency of construction organization is evident in its mobility when investing in innovations and in quick making a profit through short-term monopoly status when using innovations. This criterion is achieved through constructive and technological correspondence of ecological safety of products at a certain stage of development, organizational and technological forms at the margin of fully-automatic construction operations. This concept is based on the assumption of the existence of the regularities of the development of construction projects, construction equipment and technologies: circular, development potential wave shift of all types of construction projects and technologies; safe-hierarchical and safe integration development of the construction industry; modularity and specialization of building companies; organizational-technological balance of security potential of construction products and operations [10].

Environmental expertise of construction drifts sets the possible types of innovative construction products, so it is necessary to evaluate:

- the general growth trend of ecological safety and construction products level;

- changing of ecological safety level in the past and in the future;

- ways to ensure ecological safety of technologies in related fields;

- international trends in the development of environmentally sound construction operations and the types of innovative construction products in the world.

In the generalized development aim, different indicators are taken into account, however, in the first place, there must be a permanent level increase of ecological safety of products, both for the consumer and for the construction product manufacturer.

Option (fragment) of knowledge base architecture for environmental analysis of the innovative potentials of building technologies is schematically depicted in fig. 1, where potential points of introduction of environmentally oriented innovations are marked at the levels of the structure of possible innovations.

Environmental expertise of innovation takes into account: composition of environmental hazards in processing facility and structure of dangerous objects relationships in this facility (matrix of environmental state parameters, matrix of state parameters of building complex elements, including recorded resources - energy, material, financial, labor, research, information, natural and environmental). Environmentally 
oriented innovations bring the level development of ecological safety of construction products and production processes under achievement of society vision [3].

\section{Levels of the structure of ecologically-oriented innovative construction potentials}

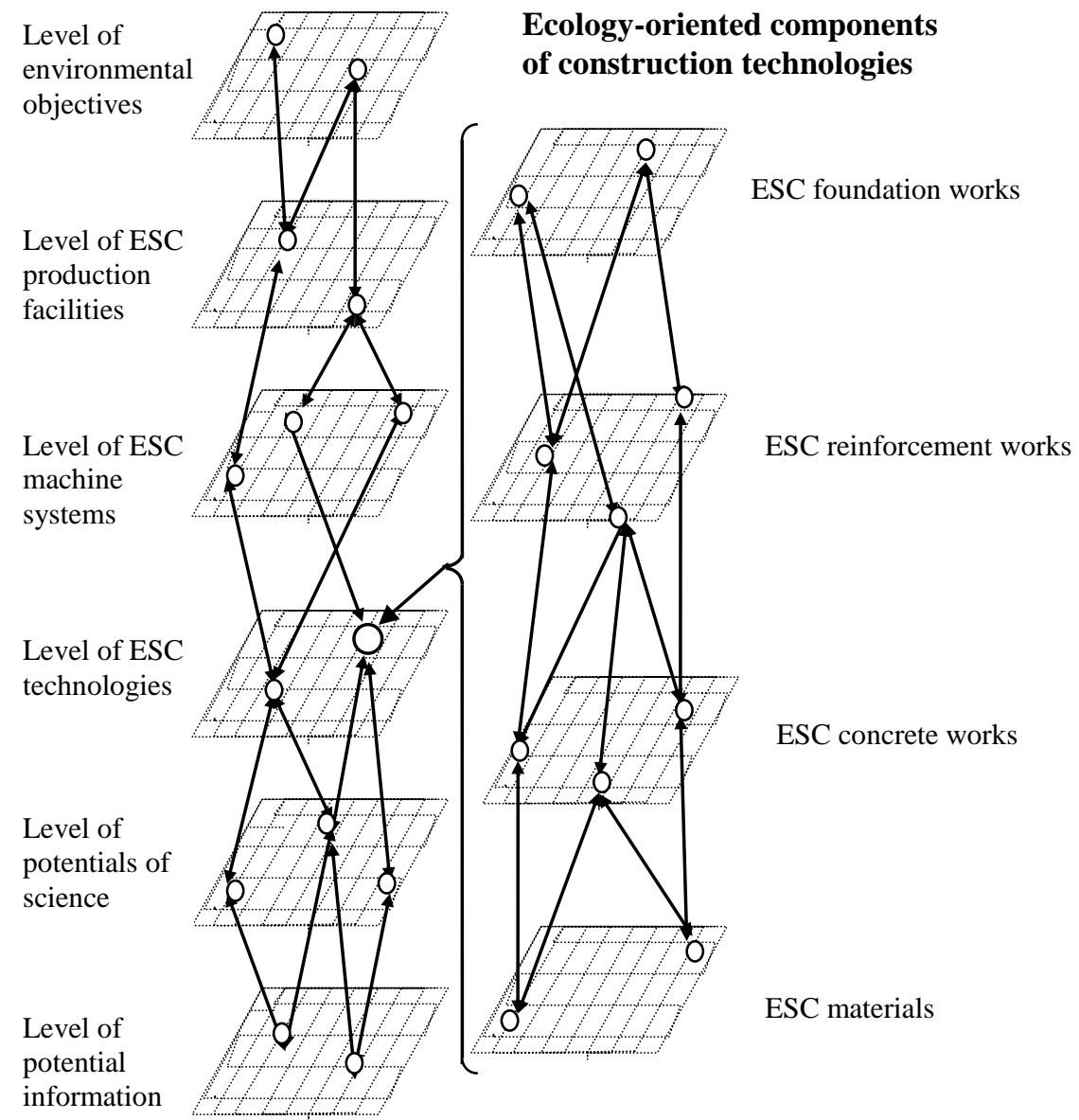

Fig. 1. Formation of innovative environmentally oriented construction technologies

The final stage of the environmental impact assessment of innovation is the formalization of collating and analyzing the results of survey and normative forecasting of the building industry. The main solution methods are methods of coordination and optimization of complex, hierarchical systems, multi-level cooperative games, simulation modeling and scenarios. Taking into account the interdisciplinary nature of forecasting of construction products and production processes indicates the desirability of taking compositional approaches to solution with provision for integration of design, technological and organizational forecasting for the level of ecological safety in the construction industry.

Possible transitions of innovative potentials of different structural design levels, manufacture and operation are indicated by the arrows (fig. 1). The choice of environmentally oriented innovative version of the critical path, made up of growing points and transition arrows of innovative environmentally oriented potential, is carried out. 
Forecasting of innovations in the construction is based on the analysis of dynamics of patenting and cataloging of generations of construction projects, construction machinery and technologies, collectively making up the technological structures in the information area at the interval of time. Projected levels of ecological security are characterized by mathematical expectation and variance of each indicator of construction technology for a certain forecasting period.

Research forecasting as examination element of innovations is carried out using probabilistic estimation methods. In fig. 2, probability of ecological safety level is determined by forecasting the limits of danger (8-shaped curves of maximum and minimum parameters admissibility or indicators of ecological safety level for construction products) or through prescribed probability distribution function, i.e. by specifying, in addition to the coves maximum (1) and minimum (3), also the highest probability (2).

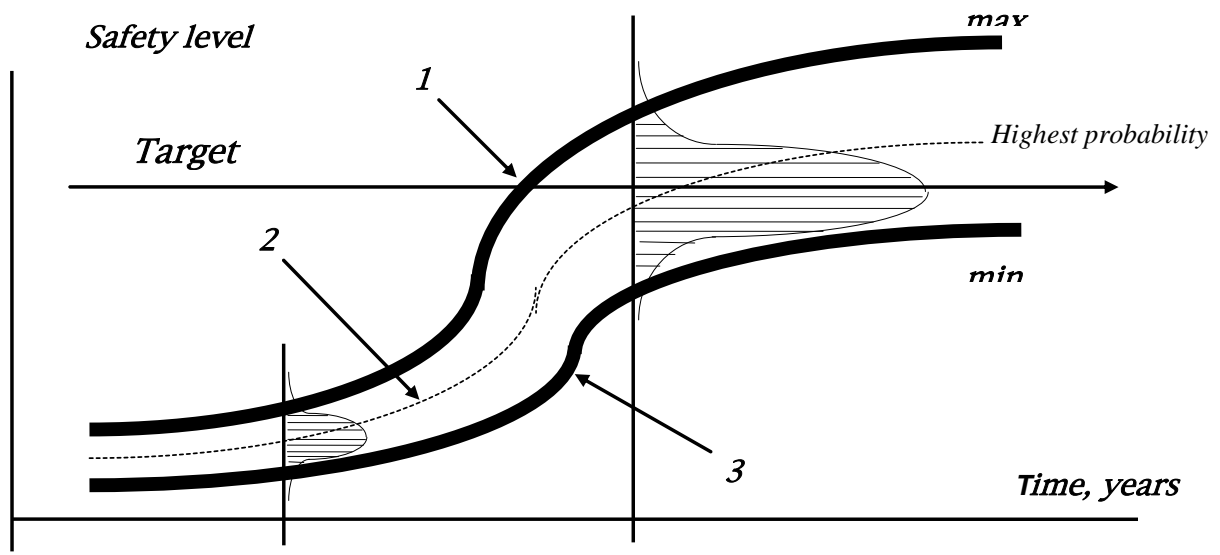

Fig. 2. Model of increasing of ESC level of local object, territory, branch

Possible variants of environmentally oriented development are analyzed on the totality of the priority directions of the development of new generations of construction technologies, new generations of buildings and construction equipment, new generations of building structural materials combined into a functional technical building systems, building plants and building production systems that are integrated into the infrastructure in relation to construction products consumer.

As a result of direct search for environmentally oriented options, the critical points of intensive growth of innovation potentials of construction products and processes on the level state matrices are determined, which are the justification for the definition of critical construction technologies and evaluation of innovations in construction. Selection of potential environmentally oriented innovations in construction brings its development under achievement of ecology goals.

\subsection{Method of solving the innovative ecological problems by linear programming}

A significant part of the tasks on decision-making in ESC systems is resource allocation between technical and natural objects.

Let $\boldsymbol{m}$ kinds of components of the environment (land, water, air, wildlife) have the appropriate resource level. The presence of each $\boldsymbol{i}$-th type of resource is $\boldsymbol{b i}(\boldsymbol{i}=\boldsymbol{l} . . . \boldsymbol{m})$ in the appropriate units of measure. These resource components can be used by natural or technical production systems - a total of $\boldsymbol{n}$ systems types. To ensure reference (reserved for natural systems and/or regulatory for technical one) environmental status of unit of $\boldsymbol{j}$-th 
system type, $\boldsymbol{a}_{i j}$ units of $\boldsymbol{i}$-th resource component type are needed. You need to determine what type and how many systems you should save that such a package to be the best for the accepted criterion of optimality. The purpose of the task on resource allocation is set by any one of the statements:

- with given resource base, maximize the result obtained, for example, approximate the environmental performance of the territory to the value of the reserve or wildlife refuge, reconstructing or reducing all or part of the industrial activity;

- with a given result, minimize the required resources, for example, with current profile, including production engineering systems in the territory, minimize the consumed resources and environmental pollution.

Denote by $x_{j}$ the number of admissible quantities of the $\boldsymbol{j}$-th type of systems. Then for the $\boldsymbol{i}$-th type of the component resource, we can write $\sum_{j=1}^{n} a_{i j} x_{i} \leq b_{i}$, where the left-hand side of the inequality expresses the need for a resource of the $\boldsymbol{i}$-th type, the right-hand side is the available quantity of this resource. Extending to $\boldsymbol{m}$ kinds of resources, this constraint can be written down:

$$
\sum_{j=1}^{n} a_{i j} x_{i} \leq b_{i}(i=1 \ldots m)
$$

If the nomenclature of systems kinds is limited to maximum number and the values of their volumes, then the following boundary conditions will be written:

$$
\underline{N}_{j} \leq x_{j} \leq \bar{N}_{j}(j=1 \ldots n)
$$

where $\underline{N}_{j}, \bar{N}_{j}$ are respectively minimum and maximum allowed volumes and/or quantity of $\mathrm{j}$-th systems types.

First statement:

$$
\left\{\begin{array}{l}
\max L_{1}=\sum_{j=i}^{n} c_{j} x_{j} ; \\
\sum_{j=i}^{n} a_{i j} x_{j} \leq b_{i}(i=1 \ldots m) ; \\
\underline{N}_{j} \leq x_{j} \leq \bar{N}_{j}(j=1 \ldots n)
\end{array}\right\}
$$

Second statement: where $\boldsymbol{x}_{\boldsymbol{j}}$ is allowed number of $\boldsymbol{j}$ - $\boldsymbol{t h}$ systems types - target variable $(\mathrm{j}=1 \ldots \mathrm{n})$; $\boldsymbol{n}$ - a number of system names; $c_{j}$ - a value that shows the contribution of the unit system of the $\boldsymbol{j}$-th type to the result; $\boldsymbol{b}_{\boldsymbol{i}}$ - a specified number of resource component of $\boldsymbol{i}$-th kind $(\mathrm{i}=1 \ldots \mathrm{m})$; $\boldsymbol{m}$ - a number of system resourcecomponents names; $\boldsymbol{a}_{i j}$ - a resource expenditure rate. 


$$
\left\{\begin{array}{l}
\min L_{2}=\sum_{i=i}^{m} y_{i} \\
\sum_{j=1}^{n} c_{j} x_{j} \geq C \\
\sum_{j=i}^{n} a_{i j} x_{j} \leq b_{i}(i=1 \ldots m) \\
\underline{N}_{j} \leq x_{j} \leq \bar{N}_{j}(j=1 \ldots n) \\
\mathrm{y} \geq \mathrm{O}(i=1 \ldots m)
\end{array}\right\}
$$

where C- minimum allowed value of result. The solution of the problem gives the determination of the values of $\mathrm{x}_{\mathrm{j}}$, which ensure the maximal result for the given resource components. The first and second problems, in which the variables $\mathrm{x}$ are composed as first degree - linear environmental programming problems.

Developed method of solving the innovative ecological problems by linear programming is to determine:

- vertices of admissible impact area as intersection points of constraints;

- the value of the objective function of exposure in vertices;

- vertex, in which the objective function of the exposure becomes extreme (max or min), is optimal;

- optimal vertex coordinates are the optimal values of the required variable factors of innovation impact.

\section{Conclusion}

Construction science strives to maximize profits with respect to mass production and intensified efforts for the marketing of the end products. In the modern concept of socioeconomically oriented marketing, intellectual efforts of construction science must become environmentally oriented towards fulfilling the needs of end consumers of buildings and other structures. As such, this study attemped to devise innovative methods of formation for ecological safety systems of constructions. For the first time, formation of innovative methods for ecological safety of construction which called to treat as a result a complex of new technical solutions (more than 15 patents for inventions) focused on the solution of ecological safety problem in construction areas, and also for the first time the set four projects of national standards "“Green" standard. "Green” technologies of living environment and "green" innovative production»: - "Terms and definitions"; "Classification"; - "Criteria of reference"; - "Conformity assessment according to the requirements of the green standards. General provisions".

\section{References}

1. M. Slesarev, Nguyen Dinh Dap, MATEC Web of Conferences, 196, 040222 (2018)

2. Yu. Evtushenko, Methods of solving extreme problems and their application in optimization systems (Moscow, EDP Science, 432, 1982)

3. M. Slesarev, IOP Conference Series: Materials Science and Engineering, 365, 022038 (2018)

4. V. Telichenko, M. Slesarev, Vestnik MGSU, 13, 5, 558-567 (2018)

5. M. Slesarev, IOP Conference Series: Materials Science and Engineering, 365, 022055 (2018)

6. M. Slesarev, VII International Symposium APCSCE (Novosibirsk, Russia, 253, 2018)

7. E. Shaviva, S. Pushka, Energy Procedia, 57, 1686-1705 (2014)

8. A. Sccott, Journal of Green building, 1, 11-27 (2006) 
9. V. Telichenko, M. Slesarev, VII International Symposium APCSCE (Novosibirsk, Russia, 254, 2018)

10. M. Slesarev, E. Pankratov, V. Fedorov, MATEC Web of Conferences, 86, 01022 (2016) 